\title{
Diplostomum spathaceum: effects of temperature and light on cercarial shedding and infection of rainbow trout
}

\author{
H. C. K. Lyholt, K. Buchmann* \\ Department of Veterinary Microbiology, Section of Fish Diseases, Royal Veterinary and Agricultural University, \\ DK-1870 Frederiksberg, Denmark
}

\begin{abstract}
The influence of temperature and light on shedding of Diplostomum spathaceum cercariae from infected Lymnaea stagnalis, collected in a Danish trout farm, was determined and the cercariae were used in infection experiments with rainbow trout Oncorhynchus mykiss. Cercarial shedding was strongly temperature dependent. Thus up to 58000 cercariae snail ${ }^{-1} \mathrm{~d}^{-1}$ were shed at $20^{\circ} \mathrm{C}$ and up to 10000 cercariae snail ${ }^{-1} \mathrm{~d}^{-1}$ at $10^{\circ} \mathrm{C}$; shedding was observed at a minimum temperature between 4 and $6^{\circ} \mathrm{C}$, which is lower than previously recorded. At constant temperature $\left(20^{\circ} \mathrm{C}\right)$ shedding was light and dark independent. The cercariae were infective at a temperature of $7^{\circ} \mathrm{C}$ although 4 to 5 times less infective than at $15^{\circ} \mathrm{C}$. Migration of the diplostomulum larva inside the fish towards the eye lens was clearly influenced by temperature: after experimental exposure to cercariae, $50 \%$ of the larvae had accumulated in the lenses of rainbow trout within 26 h at $7^{\circ} \mathrm{C}$ and within $15 \mathrm{~h}$ at $15^{\circ} \mathrm{C}$.
\end{abstract}

KEY WORDS: Eye flukes - Rainbow trout - Diplostomum - Lymnaea - Cercarial shedding - Temperature Light

\section{INTRODUCTION}

The digenean trematode Diplostomum spathaceum is a well-known parasite in fishes where it occurs as metacercaria in the eye lenses of the host and often causes parasitic cataract (Shariff et al. 1980). The helminth has been recorded from rainbow trout Oncorhynchus mykiss in a large number of countries (Buchmann et al. 1995a), and is still known to occur prevalently in some modern trout farms (Buchmann et al. 1995b). In the last few decades it has been stated that the parasite can exert a negative influence on the production of fish in aquaculture (Bauer et al. 1973, Sato et al. 1976, Stables \& Chappell 1986a), and recently, evidence of a negative association between Diplostomum infection and rainbow trout growth was provided by Buchmann \& Uldal (1994). The seasonal occurrence of fish trematodes is

- Addressee for correspondence.

E-mail: kurt.buchmann@vetmi.kvl.dk primarily determined by temperature (Chubb 1979). Likewise, infection of fishes with $D$. spathaceum is temperature dependent and field investigations have indicated that infections of fishes take place when the water temperature is at a minimum of $10^{\circ} \mathrm{C}$ (Wootten 1974, Stables \& Chappell 1986a). Investigations on the influence of temperature upon activity of this parasite have indicated that cercarial shedding from host snails (Lymnaea spp.) takes place at a minimum of 9 to $10^{\circ} \mathrm{C}$ (Bauer 1959 cited in Chubb 1979 , Brassard et al. 1982, Sous 1992). Laboratory studies have indicated that the $D$. spathaceum cercariae are able to penetrate host fishes and migrate to their eye lenses at a minimum temperature of $10^{\circ} \mathrm{C}$ (Stables \& Chappell 1986b). However, so far only a few experimental studies have been conducted to elucidate this issue. The present paper provides new information on the association among temperature, cercarial shedding and subsequent fish host infection. In addition, the influence of light on cercarial shedding was also examined. 


\section{MATERIALS AND METHODS}

Parasites. In August 1994 a total of 35 Lymnaea stagnalis and $116 \mathrm{~L}$. pereger (freshwater pulmonate snails; shell length 6 to $16 \mathrm{~mm}$ ) were collected from a Danish freshwater trout farm with prevalent Diplostomum spathaceum infections (Buchmann et al. 1995b). In addition a few L. stagnalis (shell length 33 to $40 \mathrm{~mm}$ ) were collected from the natural lake supplying the farm with water.

Each snail was placed separately in pond water in daylight at $20^{\circ} \mathrm{C}$, and $5 \mathrm{~h}$ later the water was examined for cercariae. The released cercariae were identified as Diplostomum spathaceum (according to Hoglund \& Thulin 1992) only after experimental penetration of rainbow trout and subsequent development to metacercariae in the lens of the trout (see below).

Only infected Lymnaea stagnalis were used in the expcriments described below.

Experimental fish. Rainbow trout were purchased from a parasite-free intensive trout-rearing facility based on recirculated well water.

Influence of temperature on cercarial shedding. Each infected Lymnaea stagnalis was incubated separately in dechlorinated tap water (well aerated for at least 3 d) in a thermostat-regulated incubator ( $P$ Selecta, EC 150 S, Spain) under a 15 h light: 9 h dark cycle (the same period as at the time of collection of snails). The light source was white light at 120 lux (12 $\mu E \mathrm{~m}^{-2} \mathrm{~s}^{-1}$ ), as measured with a LI-COR LI-185B photometer. The snails were fed ad libitum with fresh lettuce (Lactuca sativa). Cercarial shedding was quantified daily at temperatures between 3 and $20^{\circ} \mathrm{C}$. To examine shedding at low temperatures the snails were incubated at $10^{\circ} \mathrm{C}$ for $14 \mathrm{~d}$, followed by a gradual temperature decrease $\left(1^{\circ} \mathrm{C}\right.$ interval decrease every 4 th day until the temperature reached $3^{\circ} \mathrm{C}$ ). Thus, snails were incubated at temperatures from $10^{\circ} \mathrm{C}$ down to $3^{\circ} \mathrm{C}$ during a $42 \mathrm{~d}$ period.

Cercarial counts. The number of cercariae shed from the individual snails was quantified by exchanging the incubation water daily. The cercariae were dispersed in the water by stirring and than 3 samples (250 to $1000 \mu l$ ) were taken. Formaldehyde was added to the samples, the cercariae were counted and the number of cercariae shed per snail per day was calculated.

Influence of light upon shedding of Diplostomum spathaceum cercariae from Lymnaea stagnalis. The influence of light was examined for $5 \mathrm{~d}$ at a constant temperature $\left(20^{\circ} \mathrm{C}\right)$. The source of light was as described above. On Days 1 to 3 infected snails were incubated under a $15 \mathrm{~h}$ light : 9 h dark cycle; on Days 4 and 5 the cycle was reversed to 15 h darkness during the day and $9 \mathrm{~h}$ light at night. The number of shed cercariae was determined for each light and dark period as described above and calculated as number of cercariae released per snail per hour.

Life span of Diplostomum spathaceum cercariae. The life span of cercariae shed from Lymnaea stagnalis was examined at 4,10 and $20^{\circ} \mathrm{C}$. Five plastic vials (volume $10 \mathrm{ml}$, diameter $3 \mathrm{~cm}$ ) each containing 10 cercariae ( $<5 \mathrm{~h}$ old) in $5 \mathrm{ml}$ dechlorinated tap water were placed at each temperature. The vials were examined for living cercariae once every $24 \mathrm{~h}$; inactive cercariae were recorded as alive when the cercariae could be stimulated to move by gently touching them with a needle.

Infection experiments with Diplostomum spathaceum cercariae. These experiments were conducted with tap water ( $\mathrm{pH} 7.43$ to 7.46), using uninfected rainbow trout and cercariae shed from Lymnaea stagnalis. The cercariae were defined as infective when they were abie to penetrate test îishes and develop to metacercariae in the fishes' eye lenses.

Determination of minimum temperatures (below $10^{\circ} \mathrm{C}$ ) for infection. At 5 and $7^{\circ} \mathrm{C}$ (control: $15^{\circ} \mathrm{C}$ ) each trout (1.4 l water per fish) was exposed to 700-900 cercariae (shed at 7 and $20^{\circ} \mathrm{C}$ ) over a period of $48 \mathrm{~h}$. Then the fish were killed and the metacercariae in the lenses were counted (see Table 1). The mean weight and length of the trout were $7.8 \mathrm{~g}(\mathrm{SD}=2.6)$ and $8.8 \mathrm{~cm}$ $(\mathrm{SD}=0.97)$, respectively.

Accumulation rate of metacercariae in lenses ( 7 and $\left.15^{\circ} \mathrm{C}\right)$. Cercariae $(<5 \mathrm{~h}$ old) shed from Lymnaea stagnalis at $20^{\circ} \mathrm{C}$ were used to infect 40 rainbow trout with a mean weight of $3.5 \mathrm{~g}(\mathrm{SD}=1.2)$ and a mean length of $7 \mathrm{~cm}(\mathrm{SD}=0.8)$. Each fish (0.4 I water per fish) was exposed to 220 cercariae at $15^{\circ} \mathrm{C}$ for $1 \mathrm{~h}$. Then the trout were moved to water without cercariae: 20 fish were kept at $20^{\circ} \mathrm{C}$ and 20 were kept at $7^{\circ} \mathrm{C}$ in a thermostatregulated incubator (P-Selecta, EC $150 \mathrm{~S}$ ). After the start of infection 2 trout from each incubation temperature were killed every $4 \mathrm{~h}$ and the Diplostomum spathaceum larvae in the lenses were counted until $48 \mathrm{~h}$ post-penetration.

\section{RESULTS}

Of the collected snails, $3.4 \%$ of the Lymnaea pereger and $2.9 \%$ of the L. stagnalis shed Diplostomum spathaceum cercariae but only those from $L$. stagnalis were used in the experiments.

Daily shedding reached a maximum of 58000 cercariae snail ${ }^{-1} \mathrm{~d}^{-1}$ at $20^{\circ} \mathrm{C}$ (Fig, 1) and a maximum of 10000 cercariae snail ${ }^{-1} \mathrm{~d}^{-1}$ at $10^{\circ} \mathrm{C}$ (Fig. 2). Shedding was observed at minimum temperatures between 4 and $6^{\circ} \mathrm{C}$ (Fig. 3), where the host snails became lethargic. The cercarial shedding from Lymnaea stagnalis 


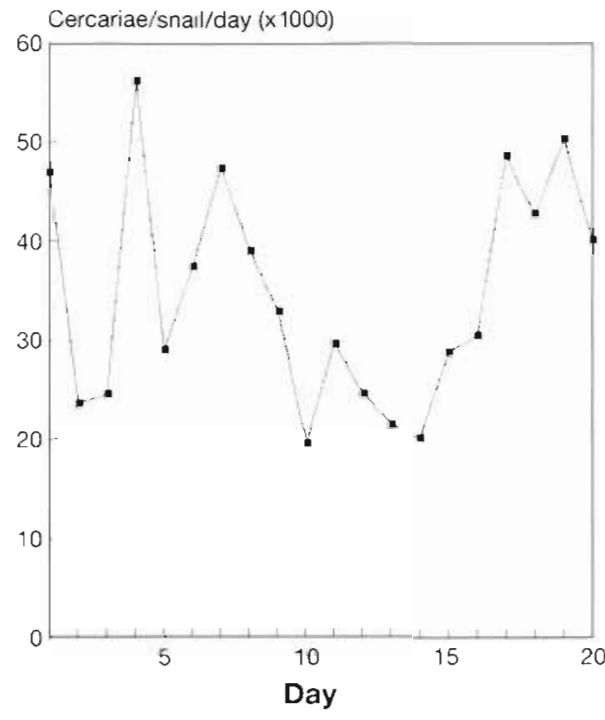

Fig. 1. Shedding of Diplostomum spathaceum cercariae from Lymnaea stagnalis at $20^{\circ} \mathrm{C}$ during a period of $20 \mathrm{~d}$ (shell length $36 \mathrm{~mm}$ )

appeared to be light and dark independent (Fig. 4). To examine the lower threshold of temperature for shedding the snails were incubated for $42 \mathrm{~d}$ at temperatures from $10^{\circ} \mathrm{C}$ down to $3^{\circ} \mathrm{C}$, as described in the 'Materials and methods' In the $42 \mathrm{~d}$ investigation period the snails shed cercariae continuously for the first 30 to $38 \mathrm{~d}$ until the temperature was lowered to between 3 and $5^{\circ} \mathrm{C}$, respectively.

The life span of the cercariae after shedding was temperature dependent: the maximum life span was 216,96 and 48 h at 4,10 and $20^{\circ} \mathrm{C}$, respectively (Fig. 5).

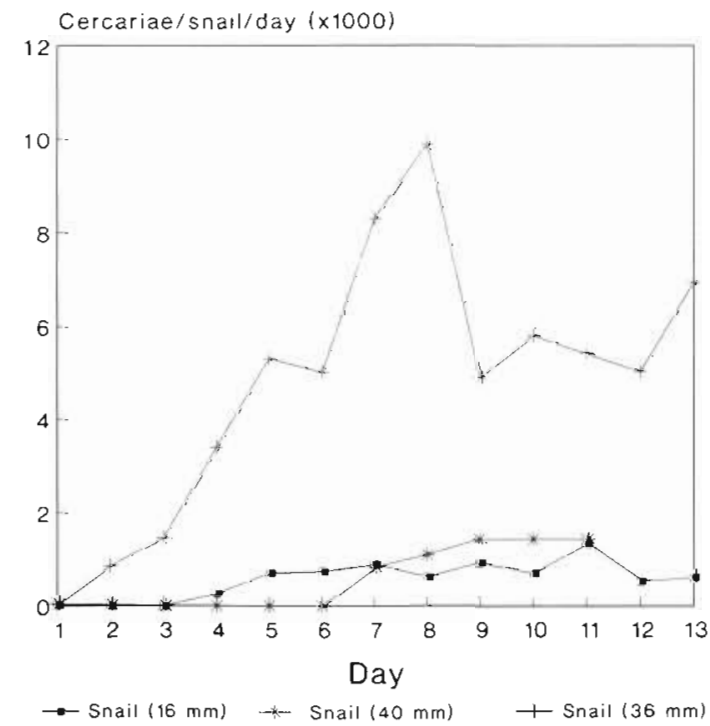

Fig. 2. Shedding of Diplostomum spathaceum cercariae from 3 specimens of Lymnaea stagnalis at $10^{\circ} \mathrm{C}$ during a period of $13 \mathrm{~d}$ (shell length indicated)

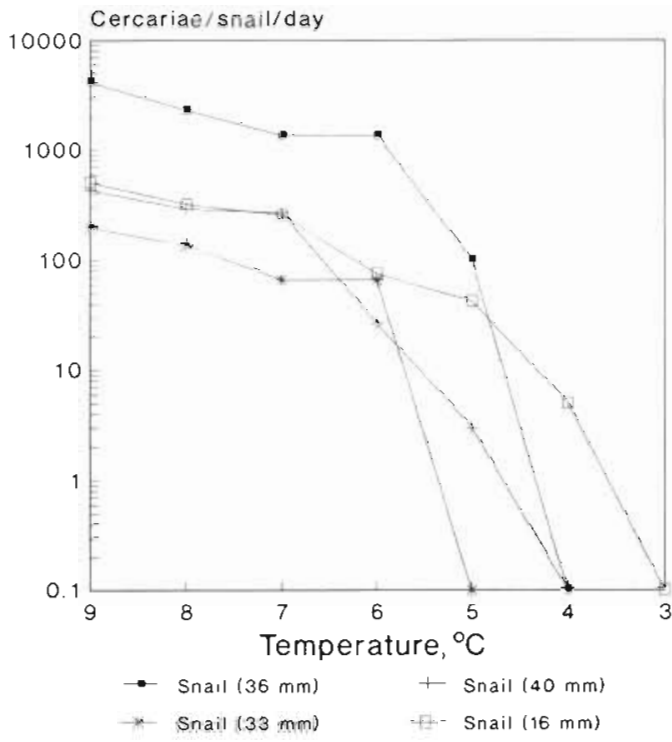

Fig. 3. Shedding of Diplostomum spathaceum cercariae from 4 specimens of Lymnata stagnalis (shell length indicated) at temperatures below $10^{\circ} \mathrm{C}$. The points represent the mean of 3 d daily shedding

Cercariae shed at 7 and $20^{\circ} \mathrm{C}$ were infective at $7^{\circ} \mathrm{C}$, but the cercariae were 4 to 5 times more infective at $15^{\circ} \mathrm{C}$ than at $7^{\circ} \mathrm{C}$ (Table 1). At $5^{\circ} \mathrm{C}$ the cercariae were not able to infect the lenses of trout. Within the trout, the migration rate of the diplostomulum larva towards the eye was temperature dependent: following infection, $50 \%$ of the larvae had accumulated in the lenses after 26 h at $7^{\circ} \mathrm{C}$ and after $15 \mathrm{~h}$ at $15^{\circ} \mathrm{C}$ (Fig. 6) (where $100 \%$ is the mean of eye flukes per trout from 28 to $48 \mathrm{~h}$ post-exposure.

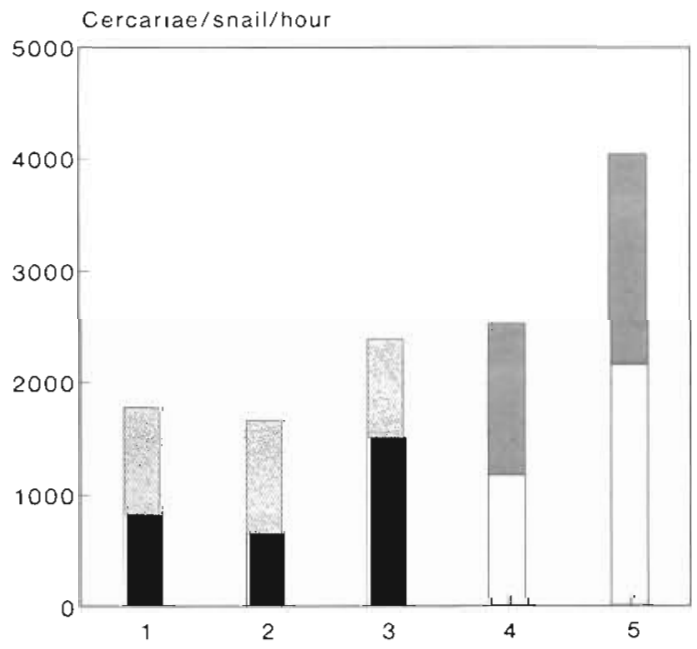

Day 1-3: light/dark; day 4-5: dark/light

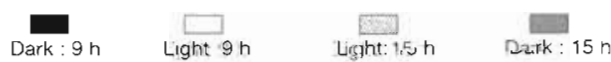

Fig. 4. Shedding of Diplostomum spathaceum cercariae from Lymnaea stagnalis in light and dark periods before and after reversal of illumination cycle 
Table 1 Infection experiments in which Oncorhynchus mykiss were exposed to cercariae from Lymnaea stagnalis at 3 different temperatures. Age of cercariae is the time from shedding until fish exposure; results for metacercariae are the no. of metacercariae recovered in the lens $48 \mathrm{~h}$ post exposure

\begin{tabular}{|c|c|c|c|c|}
\hline Exposure temperature & $7^{\circ} \mathrm{C}$ & $5^{\circ} \mathrm{C}$ & $15^{\circ} \mathrm{C}$ & $7^{\circ} \mathrm{C}$ \\
\hline Shedding temperature & $20^{\circ} \mathrm{C}$ & $20^{\circ} \mathrm{C}$ & $20^{\circ} \mathrm{C}$ & $7^{\circ} \mathrm{C}$ \\
\hline Age of cercariae & $<5 \mathrm{~h}$ & $<5 \mathrm{~h}$ & $<5 \mathrm{~h}$ & $<72 \mathrm{~h}$ \\
\hline No. of cercariae fish ${ }^{-1}$ & 800 & 900 & 800 & 700 \\
\hline No. of trout group ${ }^{-1}$ & 6 & 3 & 6 & 5 \\
\hline \multicolumn{5}{|l|}{ Metacercariae trout ${ }^{-1}$} \\
\hline Mean & 45.3 & 0 & 203.0 & 19.6 \\
\hline (SD) & $(13.4)$ & 0 & $(64.7)$ & $(5.6)$ \\
\hline Range & $24-66$ & - & $100-290$ & $12-26$ \\
\hline
\end{tabular}

\section{DISCUSSION}

The minimum temperature for transmission of Diplostomum spathaceum between host sndil and fish was previously stated to be 9 to $10^{\circ} \mathrm{C}$ (Berrie 1960 , Brassard et al. 1982, Stables \& Chappell 1986a, b). In the present work cercarial shedding from Lymnaea stagnalis was observed at a temperature as low as 4 to $6^{\circ} \mathrm{C}$. Cercarial shedding of this trematode at these low temperatures has not been reported before. The host snails were acclimatized slowly to low temperatures (by lowering the temperature from 10 to $3^{\circ} \mathrm{C}$ over 6 wk before the threshold was reached). During this period continuous shedding was observed until the snails became lethargic at 3 to $5^{\circ} \mathrm{C}$ and ceased shedding cercariae. This indicates that development

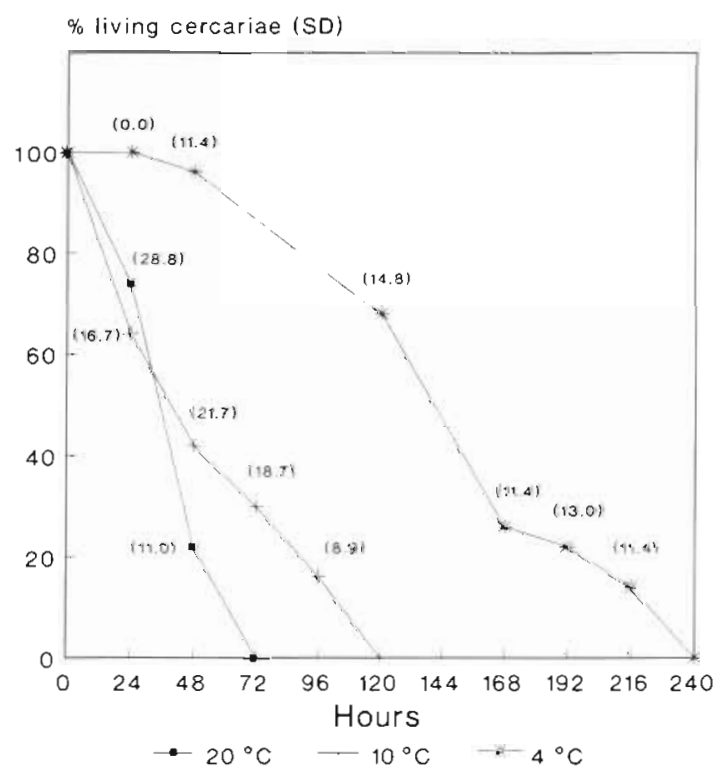

Fig. 5. Survival of Diplostomum spathaceum cercariae at 3 temperatures during a period of $240 \mathrm{~h}$. Values above individual points represent $S D$

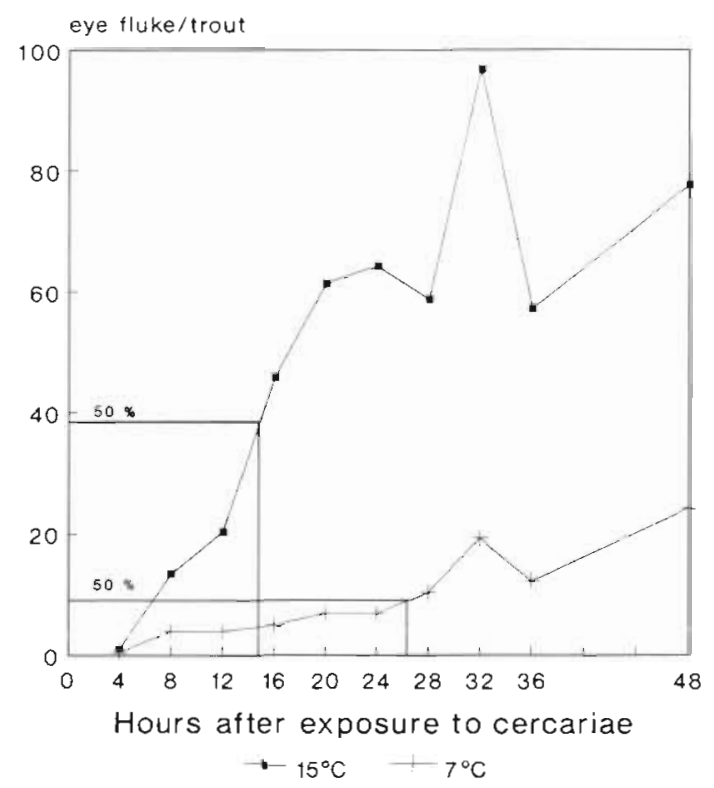

Fig. 6. Diplostomum spathaceum infecting Oncorhynchus mykiss. Accumulation of diplostomulum larvae in the eye lenses of rainbow trout at 7 and $15^{\circ} \mathrm{C}$. The time span until $50 \%$ of the larvae had entered the lenses is indicated for each temperature

and maturation of cercariae take place at temperatures below $10^{\circ} \mathrm{C}$. An investigation of trematodes in Danish freshwaters conducted half a century ago stated that $D$. spathaceum cercariae might develop in L. stagnalis at temperatures as low as $7^{\circ} \mathrm{C}$ (Wesenberg-Lund 1934). The coincidence of the threshold of shedding and the lethargic condition of the host snails indicates that the activity of the sporocysts is dependent on the metabolism of the host. Dependence of parasite activity on the metabolism of the host mollusc has been well documented in investigations of other trematode species (Smyth \& Halton 1983). Shedding of $D$. spathaceum cercariae from $L$. stagnalis was shown to be light and dark independent, which is in accordance with previous studies (Sous 1992). Other digenean cercariae released only during the light period are adapted to hosts which enter the biotope during the day (Smyth \& Halton 1983). Eye flukes, however, use aquatic organisms as both first and second intermediate hosts. Therefore they do not need light dependent shedding to optimize their life cycle efficacy, provided the infection of the second intermediate host is light independent as well. This, however, is still not known.

It has been stated (Wootten 1974. Brassard et al. 1982, Stables \& Chappell 1986a) that infection of fishes with Diplostomum spathaceum does not occur at temperatures below $10^{\circ} \mathrm{C}$. Stables \& Chappell (1986b) found by experimentation that the cercariae pene- 
trated the surface of trout at $75^{\circ} \mathrm{C}$ but that, within the fish, the migration of the parasite towards the eye was completely inhibited at this temperature. In contrast, we demonstrated that cercariae (shed at both 7 and $20^{\circ} \mathrm{C}$ ) were in fact able to penetrate the fish and subsequently infect its eyes at $7^{\circ} \mathrm{C}$. Stables \& Chappell (1986b) examined their test fishes $24 \mathrm{~h}$ after exposure with cercariae, which is the time required by $D$. spathaceum larvae to reach the eye of the fish at temperatures above $10^{\circ} \mathrm{C}$ (Ratanarat-Brockelman 1974 , Höglund 1991, Whyte et al. 1991). However, as shown in the present work this time period is prolonged at lower temperatures. Therefore, at 5 and $7^{\circ} \mathrm{C}$ we examined the test fishes up to $48 \mathrm{~h}$ post-exposure.

The life span of infective free-living stages of a number of trematode species is negatively correlated with temperature and is dependent on the consumption of stored nutrients, which itself is temperature dependent (Smyth \& Halton 1983). In the present work it was found that the life span of the Diplostomum spathaceum cercariae is also temperature dependent, and it is supposed that the diplostomulum larva migrating inside the fish also has a relatively long life span at relatively low temperatures. This could explain why at $7^{\circ} \mathrm{C}$ more than $50 \%$ of the larrae reached the lenses later than $24 \mathrm{~h}$ postpenetration.

It was observed that the intensity of the Diplostomum spathaceum transmission between host snail and fish is highly dependent on temperature. This is in accordance with previous reports (Whyte et al. 1991). But in addition, this study has provided evidence that fish are infected at temperatures as low as $7^{\circ} \mathrm{C}$. This is in conflict with earlier work in which the season for reinfection is stated to include those months in which the water temperature is at least $10^{\circ} \mathrm{C}$. There may exist different ecotypes of $D$. spathaceum with different temperature optima. We suppose that the season of reinfection of fishes with certain $D$. spathaceum ecotypes is not strictly limited to periods with at least $10^{\circ} \mathrm{C}$, but that fishes might be infected at temperatures below $10^{\circ} \mathrm{C}$ either in early spring where snails with ripe sporocysts can overwinter (Brassard et al. 1982, Sous 1992) or in late autumn before the snails enter hibernation (present work).

Acknowledgements. This study was supported by The Danish Veterinary and Agricultural Research Council and The Elisabeth and Knud Petersen Foundation.

Responsible Subject Editor: W. Körting, Hannover, Germany

\section{LITERATURE CITED}

Bauer ON, Musselius VA, Strelkov Yu A (1973) Diseases of pond fishes. [Translated from Russian.| Israel program for Scientific Translations, Jerusalem

Berne AD (1960) Two Diplostomulum larvae (Strigeida: Trematoda) in the eyes of sticklebacks (Gasterosteus aculeatus L.). J Helminthol 34:211-216

Brassard P, Curtis MA, Rau ME (1982) Seasonality of Diplostomum spathaceum (Trematoda: Strigeidae) transmission to brook trout (Salvelinus fontinalis) in northern Quebec, Canada. Can J Zool 60:2258-2263

Buchmann K, Uldal A (1994) Effects of eyefluke infections on growth of rainbow trout (Oncorhynchus mykiss) in a mariculture system. Bull Eur Ass Fish Pathol 14:104-107

Buchmann K, Uldal A, Lyholt HCK (1995a) A checklist of metazoan parasites from rainbow trout (Oncorhynchus mykiss). Acta Vet Scand 36:299-318

Buchmann K, Uldal A, Lyholt HCK (1995b) Parasite infections in Danish trout farms. Acta Vet Scand 36:283-298

Chubb JC (1979) Seasonal occurrence of helminths in freshwater fishes. Adv Parasitol 17:141-313

Höglund J (1991) Ultrastructural observations and radiometric assey on cercarial penetration and migration of the digenean Diplostomum spathaceum in the rainbow trout Oncorhynchus mykiss. Parasitol Res 77:283-289

Höglund J, Thulin J (1992) ldentification of Diplostomum spp. in the retina of perch Perca fluviatilis and the lens of roach Rutilus rutilus from the Baltic Sea - an experimental study. Syst Parasitol 21:1-19

Ratanarat-Brockelman C (1974) Migration of Diplostomum spathaceum (Trematoda) in the fish intermediate host. Z Parasitenkde 43:123-134

Sato T, Hoshina T, Horiuchi M (1976) On worm cataract of rainbow trout in Japan. Bull Jap Soc Scl Fish 42:249

Shariff M, Richards RH, Sommerville C (1980) The histopathology of acute and chronic infections of rainbow trout Salmo gairdneri Richardson with eye flukes, Diplostomum spp. J Fish Dis 3:455-465

Smyth JD, Halton DW (1983) The physiology of trematodes, 2nd edn. Cambridge University Press, Cambridge

Sous SM (1992) Influence of abiotic factors on emission and survival of cercariae of Diplostomum chromatophrum (Brown, 1931) (Trematoda, Diplostomidae). Ecol Parasitol 1(2):154-157

Stables JN, Chappell LH (1986a) The epidemiology of diplostomiasis in farmed rainbow trout from north-east Scotland. Parasitology 92:699-710

Stables JN, Chappell LH (1986b) Diplostomum spathaceum (Rud. 1819): effects of physical factors on the infection of rainbow trout (Salmo gairdneri) by cercariae. Parasitology 93:71-79

Wesenberg-Lund C (1934) Contributions to the development of the Trematoda Digenea. Part II. The biology of the freshwater cercariae in Danish freshwaters. Dan Vidensk Selsk Skr, Naturvidensk Math Afd 9(5):1-223

Whyte SK, Secombes CJ, Chappell LH (1991) Studies of the infectivity of Diplostomum spathaceum in rainbow trout (Oncorhynchus mykiss). J Helminthol 65:169-178

Wootten R (1974) Observations on strigeid metacercariae in the eyes of fish from Hanningfield Reservoir, Essex, England. J Helminthol 48:73-83

Manuscript first received: August 20, 1995

Revised version accepted: November 6, 1995 